\title{
Abbreviations
}

$\begin{array}{ll}\text { AU } & \text { African Union } \\ \text { CC } & \text { Carter Center } \\ \text { CIS } & \text { Commonwealth of Independent States } \\ \text { CW } & \text { Commonwealth of Nations } \\ \text { EC } & \text { European Commission } \\ \text { ECOWAS } & \text { Economic Community of West African States } \\ \text { EU } & \text { European Union } \\ \text { IFES } & \text { International Foundation for Electoral Systems } \\ \text { IGO } & \text { Intergovernmental Organization } \\ \text { IO } & \text { International Organization } \\ \text { IRI } & \text { International Republican Institute } \\ \text { NDI } & \text { National Democratic Institute } \\ \text { NEC } & \text { National Election Commission } \\ \text { NGO } & \text { Non-governmental Organization } \\ \text { OAS } & \text { Organization of American States } \\ \text { OSCE } & \text { Organization for Security and Cooperation in Europe } \\ \text { SADC } & \text { Southern African Development Community } \\ \text { UN } & \text { United Nations } \\ \text { UNDP } & \text { United Nations Development Programme } \\ \text { UNDPA } & \text { United Nations Department of Political Affairs } \\ \text { UNEAD } & \text { United Nations Electoral Assistance Division } \\ \text { USAID } & \text { United States Agency for International Development } \\ \text { USIP } & \text { United States Institute of Peace }\end{array}$





\section{THE CREDIBILITY}

CHALLenGe 
